interviewed in order obtain information related to onset of asthma and suspected cause of asthma. Four questions related to WRA included:

- history of asthma symptoms which get well when away from work or on holidays

- history of asthma symptoms which get worsen during the working days

- evidence of the sensitising or irritant agents in workplace that have been previously studied causing WRA

- evidence of exposure to the sensitising or irritant agents in workplace that have been previously studied causing WRA.

Descriptive statistics was used for analysis of data.

Results The proportion of WRA amongst asthmatic patients was $16.3 \%$. Of those with WRA, $69.0 \%$ were new-onset asthma $(87.9 \%$ were occupational asthma (OA) and $12.1 \%$ were reactive airways dysfunction syndrome). The remaining of $31 \%$ was work exacerbated asthma. The top three defined occupations were those working in the manufacturing, ground cleaning/waste management services and personal care and services, respectively. Considering the agents, top three agents were chloramine, metal fume and wood dust, respectively.

Conclusion The current study showed a similar result reported elsewhere where $16.3 \%$ of asthmatic patients were WRA and as expected, OA contributed most. This finding encourages physicians to explore patients' occupation and their job descriptions since they will help physicians to focus on WRA. Therefore early recognition of early-onset of WRA will help curing or improving asthma at last.

\section{OCCUPATIONAL EXPOSURE IN AGRICULTURAL WORKERS - IMPACT ON ASTHMA AND CHRONIC OBSTRUCTIVE PULMONARY DISEASE DEVELOPMENT}

S Stoleski*, J Minov, J Karadzinska-Bislimovska, D Mijakoski, A Atanasovska. Institute for Occupational Health of $R$. Macedonia, WHO Collaborating Centre and GA2LEN Collaborating Centre, Skopje, R. Macedonia

\subsection{6/oemed-2018-ICOHabstracts. 1311}

Aim of the study Determination of the occupational exposure influence on asthma and COPD development among crop and dairy farmers, and evaluation of exposure characteristics by job exposure matrices.

Methods A cross-sectional study was performed, including 87 crop farmers and 83 dairy farmers, exposed to respiratory hazards, compared to a control group of 80 office workers. Standard questionnaire on chronic respiratory symptoms and spirometry testing were applied, while farmers were also assessed by job exposure matrices.

Results and discussion Asthma was registered in $8 \%$ of crop and $7.2 \%$ of dairy farmers, and was significantly associated with atopy, and positive family history of asthma and COPD, while association with smoking habit and duration of exposure was non-significant. The prevalence of allergic was significantly higher compared to non-allergic asthma in exposed and unexposed workers. Occupational allergic asthma was registered in $2.3 \%$ of crop and $1.2 \%$ of dairy farmers, while the frequency of work-aggravated asthma was $5.7 \%$ and $6.1 \%$ respectively. COPD prevalence was non-significantly higher in exposed
(6.9\% in crop and $8.4 \%$ in dairy farmers) compared to office controls (3.8\%). COPD was significantly associated with age over 40 years, smoking habit, and duration of exposure in exposed subjects. According to data obtained by job exposure matrices, asthma and COPD in crop farmers were significantly related to high intensity of exposure to dust, gases, fumes and vapours on a regular basis, while among dairy farmers they were significantly related to high intensity of dust exposure on a regular basis, as well as high intensity of exposure to gases, fumes and vapours both on sporadic and regular basis.

Conclusion The study results confirm the impact of occupational exposure to respiratory hazards on respiratory health impairment among farmers, including asthma and COPD, being closely related to its duration, characteristics, and intensity.

\section{SMOKING AND PULMONARY ALTERATIONS IN RETIRED BAUXITE MINING WORKERS: A RETROSPECTIVE STUDY}

LR Ferreira*, LFT Priester, VL Ferreira, CM Galhardi, LCR Ferreira, RCG Bianchi. UNIFAE School of Medicine, Sao Joao da Boa Vista SP, Brazil

\subsection{6/oemed-2018-ICOHabstracts.1312}

Introduction Retired bauxite mining workers have been at risk for developing lung diseases due to their long-term exposure to inhalation hazards. Smoking is known to decrease pulmonary function and cause lung disease. Smoking cessation may prevent these changes. This study aimed to evaluate whether smoking is associated with pulmonary changes in retired bauxite mining workers.

Methods A cross-sectional study involving the database information of 140 retired bauxite mining workers from Brazil evaluated at the Worker's Health Reference Centre and Social Security National Institute, from July 2015 until June 2016. The workers were divided in 3 groups: smokers $(n=47)$, nonsmokers $(n=47)$, and ex-smokers $(n=46)$. The data included: gender, age, spirometric results (normal; altered results including mild, moderate or severe changes), and presence of pulmonary parenchymal alterations in chest $\mathrm{x}$-rays. It was applied the Chi-Squared test with $\mathrm{p}<0,05$.

Results All workers were male with mean age of 62 years-old. In the smokers group, $83 \%$ spirometry tests were altered (53\% mild, $19 \%$ moderate and $11 \%$ with severe changes). In this group, $64 \%$ had altered chest $\mathrm{x}$-rays. In the non-smokers group, $19 \%$ spirometry tests were altered (13\% mild and 6\% moderate changes). In this group, $13 \%$ had altered chest $\mathrm{x}$ rays. In the ex-smokers group, 35\% spirometry tests were altered (11\% mild, 9\% moderate and 15\% severe changes). In this group, $30 \%$ had altered $\mathrm{x}$-rays. All results were statistically significant, except for the mild changes in the non and ex-smokers groups.

Discussion These results demonstrated differences between the smokers and non-smokers groups in regard to spirometric and radiographic alterations. The ex-smokers group had improved results compared to the smokers group in regard to altered spirometric and chest $\mathrm{x}$-rays findings. These data may contribute with strategies to enhance smoking cessation programs within the bauxite mining industry in order to prevent pulmonary changes in mining workers. 